\title{
Effects of exposure to electromagnetic field (1.8/0.9 GHz) on testicular function and structure in growing rats
}

\author{
H. Özlem Nisbetat ${ }^{a *}$, Cevat Nisbet ${ }^{\mathrm{b}}$, Aysegul Akar ${ }^{\mathrm{c}}$, Mesut Cevik ${ }^{\mathrm{d}}$, M. Önder Karayigit ${ }^{\mathrm{e}}$ \\ ${ }^{a}$ Department of Surgery, Faculty of Veterinary Medicine, Ondokuz Mayls University, Samsun, Turkey \\ ${ }^{b}$ Department of Biochemistry, Faculty of Veterinary Medicine, Ondokuz Mayls University, Samsun, Turkey \\ ${ }^{c}$ Department of Biophysics, Faculty of Medicine, Ondokuz Mayls University, Samsun, Turkey \\ ${ }^{d}$ Department of Reproduction and Artificial Insemination, Faculty of Veterinary Medicine, Ondokuz Mayls University, \\ Samsun, Turkey \\ ${ }^{e}$ Department of Pathology, Faculty of Veterinary Medicine, Ondokuz, Mayls University, Samsun, Turkey
}

\section{ARTICLE INFO \\ * Correspondence to: \\ H. Özlem Nisbet \\ Department of Surgery, \\ Faculty of Veterinary Medicine, \\ Ondokuz Mayıs University, \\ Samsun, Turkey \\ e-mail: onisbet@omu.edu.tr}

\section{Keywords:}

Electromagnetic field

Epididymal sperm motility

Testicular function

Testosterone level

\section{ABSTRACT}

The aim of our study was to evaluate the possible effects of whole-body electromagnetic field (EMF) exposure on reproduction in growing male albino Wistar rats. The rats (2 days old) were randomly divided into three independent groups. The rats were exposed to EMF 1800 and $900 \mathrm{MHz}$ for 2 hours continuously per day for 90 days. Sham control was kept under similar conditions except that the field was not applied for the same period. After blood samples were collected, the animals were sacrificed $24 \mathrm{~h}$ after the last exposure and the tissues of interest were harvested. The mean plasma total testosterone showed similarity among the two study groups and was significantly higher than the sham control rats. The percentage of epididymal sperm motility was significantly higher in the $1800 \mathrm{MHz}$ group $(\mathrm{P}<0.05)$. The morphologically normal spermatozoa rates were higher and the tail abnormality and total percentage abnormalities were lower in the $900 \mathrm{MHz}$ group $(\mathrm{P}<0.05)$. Histopathologic parameters in the $1800 \mathrm{MHz}$ group were significantly higher $(\mathrm{P}<0.05)$. In conclusion, the present study indicated that exposure to electromagnetic wave caused an increase in testosterone level, epididymal sperm motility (forward), and normal sperm morphology of rats. As a consequences, 1800 and $900 \mathrm{MHz}$ EMF could be considered to be a cause of precocious puberty in growing rats.

J.Exp.Clin.Med., 2013; 30: 275 